\title{
Capture Mechanism of La and Cu lons in Mixed Solutions by Clay and Organoclay
}

\author{
Cinzia Cristiani, * Elena Maria Iannicelli-Zubiani, Maurizio Bellotto, Giovanni Dotelli, \\ Paola Gallo Stampino, Saverio Latorrata, Gianguido Ramis, and Elisabetta Finocchio
}

Cite This: Ind. Eng. Chem. Res. 2021, 60, 6803-6813

Read Online

\section{ACCESS 1}

Џ Metrics \& More

Article Recommendations

Supporting Information

ABSTRACT: In this work, Ca-montmorillonite (STx), natural and modified (STx-L6) with a linear penta-ethylene-hexamine (L6), were tested as sorbents in a liquid/solid process for La and $\mathrm{Cu}$ capture in bionic model solutions. Twelve $\mathrm{La} / \mathrm{Cu}$ ratios in solution were set and analyzed with the final target of investigating the capture mechanisms when both $\mathrm{Cu}$ and $\mathrm{La}$ are present. The liquid phase was characterized via inductively coupled plasmaoptical emission spectroscopy (ICP-OES), while the solids were studied by means of X-ray powder diffraction (XRPD). No direct competition between $\mathrm{Cu}$ and $\mathrm{La}$ ions for the capture sites was found but rather the modification of the acid-base condition of

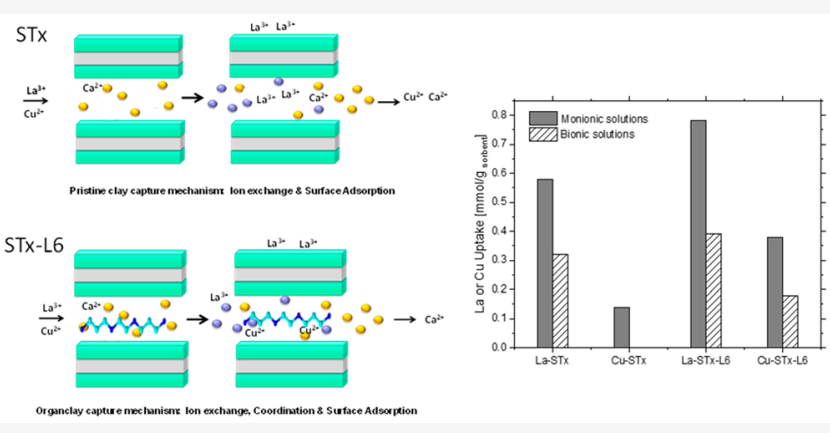
the solution and the related equilibria due to aquo- and hydroxycopper complexes formation. $\mathrm{Cu}$ complexes are responsible for $\mathrm{pH}$ modification and the related influence on the capture of La ions. Three distinct mechanisms were identified to be active in the capture process, i.e., ion exchange, surface adsorption, and coordination of the metal by the polyamine, when present. Only La is involved in the ionic exchange process, since no $\mathrm{Cu}$ was captured by pristine clays, while only $\mathrm{Cu}$ is coordinated to the polyamine, in view of its preferential interaction with amino groups. The different capture mechanisms are responsible for the higher efficiency of the organoclay, with respect to the pristine one. This study lays the groundwork for the development of an efficient method for rare earths (REs) and precious metal recovery from waste electrical and electronical equipment (WEEE) by a liquid/solid process.

\section{INTRODUCTION}

Contamination of drinking water and aquatic environmente with heavy metals and organic pollutants has attracted increasing attention because of their adverse health effects to humans and natural organisms ${ }^{1-3}$ For example, $\mathrm{Cr}, \mathrm{Cd}, \mathrm{Cu}$, or $\mathrm{Ni}$ are common pollutants worldwide, and they represent one of the major environmental problems, being able to induce acute and chronic toxicity. Thus, many scientists have addressed the process for the reduction or elimination of these ions polluting waters. Moreover, the demand of valuable metals such as $\mathrm{Cu}, \mathrm{Ni}, \mathrm{Co}$, and rare earths (REs) is constantly increasing in the global market, to be used in many different technological applications, in view of their unique properties. Since their natural resources are located in troubled world areas, they are well known as "critical raw materials". Therefore, the recovery of these metals, and others of industrial interest, from waste electrical and electronic equipment (WEEE) has been proposed. This process is the so-called "urban mining". 4

It is evident that the availability of an efficient capture process for metal recovery is of paramount importance. To date, different methods for metal ion capture from solutions have been proposed, which include chemical precipitation, ion exchange, membrane filtration, flocculation, and adsorption. Among others, solid/liquid adsorption is preferred because it does not require high operating temperatures, and it is simple. With this process, solutions containing several ions can be treated. $^{5-10}$

For this reason, the development of effective metal adsorbents and the exact knowledge of the adsorption behavior is a vital goal for industrial applications of this process. Indeed, it is important to comprehend how metal ions are transferred from the liquid phase to the bulk or the surface of the solid phase and the interaction between liquid and solid phases, as well as the adsorption mechanism. ${ }^{11,12}$

Layered double hydroxides ${ }^{13}$ and layered silicates (clays), pristine or modified, have been proposed as sorbents. They are promising host materials in view of their structure, allowing incorporation of cations, organic anions, or polymers by

Special Issue: Enrico Tronconi Festschrift

Received: October 30, 2020

Revised: January 27, 2021

Accepted: January 27, 2021

Published: February 2, 2021 
Table 1. Total, La, and $\mathrm{Cu}$ Ions Contents and Corresponding $\mathrm{pH}$ before and after Uptake Reaction Using Unmodified STx as Sorbent

\begin{tabular}{|c|c|c|c|c|c|c|c|c|c|}
\hline \multirow[b]{2}{*}{ SET N $^{\circ}$} & \multirow[b]{2}{*}{$\mathrm{La} / \mathrm{Cu}$} & \multicolumn{2}{|c|}{$\mathrm{La}+\mathrm{Cu}[\mathrm{mmol} / \mathrm{gSTx}]$} & \multicolumn{2}{|c|}{$\mathrm{La}[\mathrm{mmol} / \mathrm{gSTx}]$} & \multicolumn{2}{|c|}{$\mathrm{Cu}[\mathrm{mmol} / \mathrm{gSTx}]$} & \multicolumn{2}{|c|}{$\mathrm{pH}$} \\
\hline & & initial & capture & initial & capture & initial & capture & before & after \\
\hline \multirow[t]{4}{*}{0.47} & 1.00 & 0.94 & 0.25 & 0.47 & 0.23 & 0.47 & 0 & 4.1 & 4.4 \\
\hline & 0.38 & 1.72 & 0.20 & 0.47 & 0.20 & 1.25 & 0 & 4.2 & 4.6 \\
\hline & 0.24 & 2.47 & 0.16 & 0.47 & 0.16 & 2.00 & 0 & 4.3 & 4.4 \\
\hline & 0.19 & 2.97 & 0.14 & 0.47 & 0.14 & 2.50 & 0 & 4.1 & 4.3 \\
\hline \multirow[t]{4}{*}{1.25} & 2.66 & 1.72 & 0.33 & 1.25 & 0.33 & 0.47 & 0 & 4.2 & 4.9 \\
\hline & 1.00 & 2.5 & 0.24 & 1.25 & 0.24 & 1.25 & 0 & 4.1 & 4.5 \\
\hline & 0.63 & 3.25 & 0.20 & 1.25 & 0.20 & 2.00 & 0 & 4.0 & 4.3 \\
\hline & 0.50 & 3.75 & 0.19 & 1.25 & 0.19 & 2.50 & 0 & 3.9 & 4.3 \\
\hline \multirow[t]{3}{*}{2.50} & 5.32 & 2.97 & 0.32 & 2.50 & 0.32 & 0.47 & 0 & 4.2 & 4.8 \\
\hline & 2.00 & 3.75 & 0.30 & 2.50 & 0.30 & 1.25 & 0 & 3.7 & 4.4 \\
\hline & 1.25 & 4.5 & 0.25 & 2.50 & 0.25 & 2.00 & 0 & 3.8 & 4.3 \\
\hline
\end{tabular}

intercalation, followed by the expansion of interlayer distances. $^{14-18}$

Within this picture, clay-based materials are commonly used for a wide range of technological applications. Among others, important parameters controlling metal ions adsorption and their distribution between liquid and solid phases are the sorbent nature, metal speciation, metals concentration, $\mathrm{pH}$, solid/liquid mass ratio, and contact time. ${ }^{19-21}$

Our research group investigated capture processes using different sorbent solids, such as mineral clay (smectite) or active carbon, both pristine and modified by polyamines of different molecular weight, chain length, or structure. ${ }^{2-25}$ Among the studied polyamines, pentaethylenehexamine was demonstrated to possess the best capture capability toward $\mathrm{REs}, \mathrm{Cu}$, and $\mathrm{Ni}$ in single-ion model solutions. The roles of clay interlayer cations, amino groups, and operating parameters such as $\mathrm{pH}$ and metal concentration were pointed out for the success of the capture process. ${ }^{26}$ Also preliminary results on bionic solutions indicated the pentaethylenehexamine-based organoclay as the best performing sorbent solid in the simultaneous capture of ions. ${ }^{26}$

Different mechanisms were hypothesized for metal capture, such as cationic exchange (prevailing in pristine clay), coordination to amino groups (in organoclays), and surface adsorption at unsaturated reactive sites such as hydroxyl groups. $^{26,27}$ However, results were not conclusive in view of the limited number of experiments that did not allow for deep comprehension of the capture mechanism and phenomena related to the different affinities of each ion for the different solid sorbents, in particular in complex matrices. All these aspects are of paramount importance because, in real applications, the solutions are a mix of a large number of ions and monoionic solutions are extremely rare.

Example of real solution compositions are reported in Table S1 and Table S2 (Supporting Information). These data were obtained by analyzing scraps of real WEEE supplied by collectors within a project of the Lombardia Region, Italy. ${ }^{28}$

Considering the complexity of the solutions, a simplified approach, analyzing first monoionic solutions and subsequently solutions of increasing complexity, can be a good starting point. This way, the comprehension of each ion behavior toward capture can be evinced and subsequently evaluated in the presence of other ionic species.
For the implementation of materials and processes developed at lab scale up to the industrial level, knowledge of the ion-sorbent interactions is helpful to adapt the new materials to the "in field" situation. Therefore, a scientific explanation of the sorption mechanism could help to better manage and control the sorbent and the related process.

In previous papers, simplified solutions were studied, at the beginning containing only one ion then progressively increasing solution complexity. ${ }^{23,26,27,29}$ WEEE elemental composition can be largely variable depending on the origin; therefore, La, Y, and Nd were considered representative of rare earths, while $\mathrm{Cu}$, present in very large amount in WEEE scraps, was considered a good example of metal of economic interest.

Accordingly, the aim of this paper is to understand the behavior of the most performant sorbent solids developed in our laboratories toward metal capture in bionic $\mathrm{La}-\mathrm{Cu}$ solutions, with particular attention to the mechanisms of the ion-solid interactions.

A wide solution composition range is here proposed: 12 bionic solutions were prepared by coupling La concentrations fixed at 19,50 , and $100 \mathrm{mmol} / \mathrm{L}$ with $\mathrm{Cu}$ concentrations of 19 , 50,80 , and $100 \mathrm{mmol} / \mathrm{L}$. The initial solution concentrations were selected in a preindustrialization perspective, ${ }^{28}$ since the final aim was the treatment of wastewater coming from WEEE hydrometallurgical processes. Moreover, solution compositions were selected for the sake of comparison with those previously analyzed and reported. ${ }^{23,26,27,29}$

Bionic solutions were contacted with both the pristine and modified clay, and analyzed before and after the capture step. Sorbents have been studied to understand their behavior when $\mathrm{La}$ and $\mathrm{Cu}$ are copresent. A detailed picture of the capture mechanism is proposed for each ion and sorbent; the ions mutual influences on the final total capture efficiency is also addressed.

\section{MATERIALS AND METHODS}

A natural smectite, i.e., a Ca-montmorillonite STx-1b (Clay Minerals Society, STx in the text), of formula ${ }^{\mathrm{IV}} \mathrm{Si}_{4.0}{ }^{\mathrm{VI}}\left(\mathrm{Al}_{1.21} \mathrm{Fe}^{3+}{ }_{0.05} \mathrm{Mg}^{2+}{ }_{0.36} \mathrm{Ti}_{0.02}\right)^{\mathrm{XII}}\left(\mathrm{Ca}_{0.14} \mathrm{Na}_{0.02} \mathrm{~K}_{0.01}\right)$ $\mathrm{O}_{10}(\mathrm{OH})_{2}$ and a modified organoclay with a linear pentaethylene-hexamine (Sigma-Aldrich 99\%, L6 in the text) were used as sorbent solids.

The organoclay (STx-L6, in the text) was obtained according to a procedure previously developed in our 

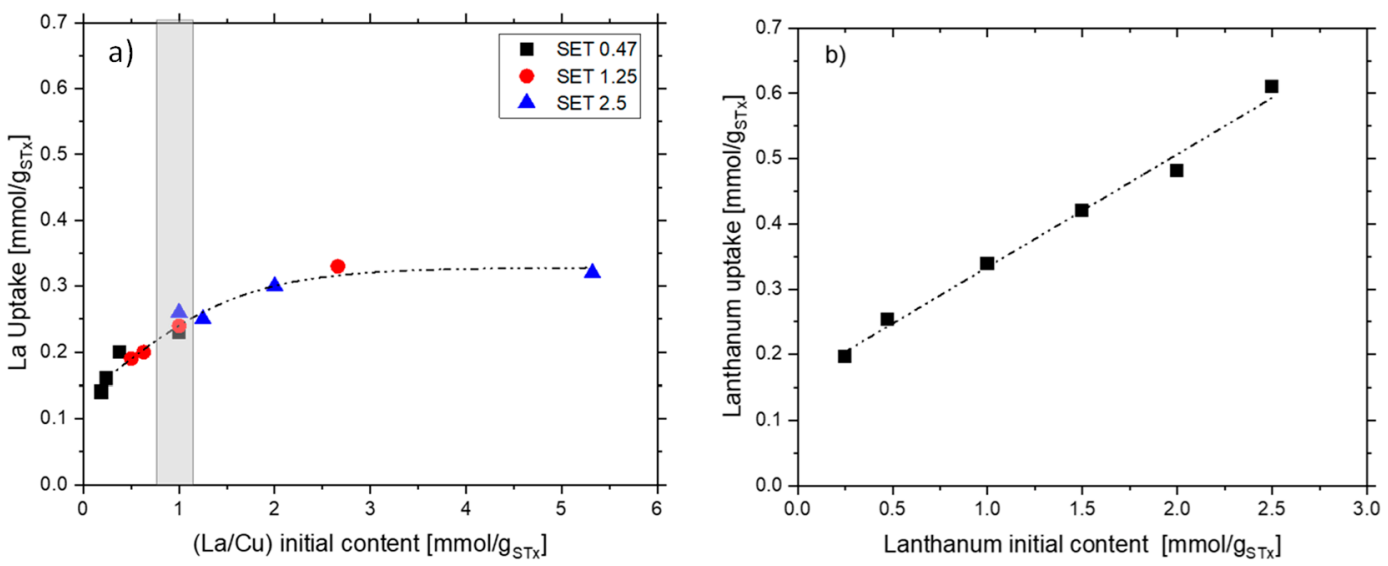

Figure 1. Lanthanum uptake by STx as a function of $\mathrm{La} / \mathrm{Cu}$ in bionic solutions (a) and lanthanum uptake as a function of La initial concentration in monoionic solutions (b). Dashed area: samples with the same $\mathrm{La} / \mathrm{Cu}$ ratio.

laboratories. ${ }^{14}$ Preparation experimental conditions were set to intercalate the polyamine in its neutral form, i.e., without ion exchange, and no formation of ammonium salts. ${ }^{14}$ The final polyamine content in the organoclay was set at $0.40 \mathrm{mmol} /$ gSTx.

Monoionic and bionic solutions were prepared starting from lanthanum nitrate $\left(\mathrm{La}\left(\mathrm{NO}_{3}\right)_{3} \cdot 5 \mathrm{H}_{2} \mathrm{O} 99.99 \%\right.$, Sigma-Aldrich) and copper nitrate $\left(\mathrm{Cu}\left(\mathrm{NO}_{3}\right)_{2} \cdot 2.5 \mathrm{H}_{2} \mathrm{O} 98 \%\right.$, Sigma-Aldrich). Other chemicals were $\mathrm{HNO}_{3}$ (ACS, Sigma-Aldrich), $\mathrm{NaOH}$ (ACS, Sigma-Aldrich), and deionized water.

For the bionic solutions, four initial $\mathrm{Cu}$ concentrations in the range of $19-100 \mathrm{mmol} / \mathrm{L}$ were chosen, while La concentrations were fixed at 19, 50, and $100 \mathrm{mmol} / \mathrm{L}$. Experiments were carried out in series of samples fixing La concentration at 19 , 50, and $100 \mathrm{~mol} / \mathrm{L}$, respectively, and varying $\mathrm{Cu}$ concentration (Table 1). Considering three La concentrations and four $\mathrm{Cu}$ concentrations, 12 capture experiments were performed using both the pristine clay and the organoclay as sorbents.

According to previous studies, $2 \mathrm{~g}$ of pristine or modified clay was contacted with $50 \mathrm{~mL}$ of solution, under stirring at room temperature for $90 \mathrm{~min}^{23}$ During the experiments, $\mathrm{pH}$ was measured (Mettler Toledo FE20/EL20 digital pH meter), but no $\mathrm{pH}$ correction was applied. After the reaction, solid and liquid phases were separated by centrifugation at $13,000 \mathrm{rpm}$ for $1 \mathrm{~h}$ (HETTICH 32 RotoFix centrifuge).

Solutions before and after uptake reactions were analyzed by inductively coupled plasma-optical emission spectrometry (ICP-OES, PerkinElmer Optima 8300). The average of three measurements is reported, and the measurement error estimated from the replicate measurements is within $1 \%$. Captured metal ions were determined by the difference between initial and residual ion content before and after the capture process. Ion determination was performed considering interferences when present.

Sorbent solids were analyzed by X-ray diffraction analysis (BRUKER D8), using $\mathrm{Cu} \mathrm{K} \alpha$ radiation of $1.5418 \AA$, filtered with a graphite monochromator. Spectra were collected at $3^{\circ}-$ $30^{\circ} 2 \theta$, applying a step scan of $0.02^{\circ} 2 \theta$ and a counting time of $1 \mathrm{~s}$ per step.

\section{RESULTS AND DISCUSSION}

In the following, the samples are identified by labels showing the solid sorbent (i.e., pristine clay, STx, or modified organoclay, STx-L6) and $\mathrm{La} / \mathrm{Cu}$ initial ratio. For example, label STx-1 identifies a sample where the applied sorbent solid was pristine clay (STx), and the ratio between $\mathrm{La}$ and $\mathrm{Cu}$ in the initial solution was equal to 1 .

In the text, metal content is expressed in terms of mmol/ $\mathrm{g}_{\text {sorbent, }}$ which allows for direct quantitative comparison between the samples. Also, in the case of the metals ratio, the measurement units are explicitly expressed for sake of clarity as a reminder to what they are referring.

1. Pristine Clay (STx). La-Cu mixed solutions were first contacted with pristine clay (STx). Results of ICP-OES analyses after the capture step are summarized in Table 1. SET numbers in the table identify initial La concentrations in the bionic solutions.

Irrespective of initial composition or ions ratio, no $\mathrm{Cu}$ uptake was observed by pristine clay in our process conditions; moreover, also a limited uptake of La ions was detected (between $50 \%$ and $12 \%$, depending on initial La content), as already observed in a previous work for similar systems. ${ }^{26}$ To explain the observed behavior, data in Table 1 have to be considered. Indeed, $\mathrm{Cu}$ is not involved in ion capture; therefore, the total uptake in these experiments corresponds to La uptake only, and $\mathrm{La} / \mathrm{Cu}$ initial ratio describes the effect of the presence of $\mathrm{Cu}$ on $\mathrm{La}$ capture.

Lanthanum capture was plotted as a function of the $\mathrm{La} / \mathrm{Cu}$ ratios in the initial solutions (Figure 1a), where symbols identify experiments performed with solutions of different initial La content.

On increasing the La absolute value in the bionic solution (i.e., increasing $\mathrm{La} / \mathrm{Cu}$ ratios), higher La uptakes were found, up to an asymptotic value (Figure 1a).This behavior was apparently insensitive of the initial absolute composition; all the data are fitted by the same curve which is a function of La/ $\mathrm{Cu}$ only. Indeed, samples contacted with solutions of equal La/ $\mathrm{Cu}$ ratios, but different composition pairings (dashed area in Figure 1a), resulted in the same La capture (i.e., 0.23, 0.24, and $\left.0.23 \mathrm{mmol} / \mathrm{g}_{\mathrm{STx}}\right)$. In addition, the La uptake maximum efficiency was lower in bionic solutions than monoionic ones; at the highest $\mathrm{La} / \mathrm{Cu}$ ratio, and for the highest $\mathrm{La}$ initial concentration, La capture in bionic systems was not higher than $0.33 \mathrm{mmol}_{\mathrm{La}} / \mathrm{g}_{\mathrm{ST} x}$, to be compared with $0.60 \mathrm{mmol}_{\mathrm{La}} / \mathrm{g}_{\mathrm{STx}}$ of the monoionic ones.

The observed capture behavior pinpoints to the hypothesis of the formation of different species in solution, depending on $\mathrm{pH}$. This hypothesis was verified a priori by Hydra-Medusa software, which is able to describe equilibria and ions 
speciation in solution on the basis of thermodynamic data. Although this calculation cannot describe precisely our solutions in real conditions, it can give preliminary information on the ions behavior as a function of $\mathrm{pH}$. Equilibrium calculations by Hydra-Medusa were performed on the La and $\mathrm{Cu}$ solutions (Figure S1, Supporting Information). It has been found that, at a working $\mathrm{pH}$ range, no $\mathrm{La}$ complexes are expected to form; on the contrary, soluble complexes formation is the most probable reaction in the case of $\mathrm{Cu}$ ions.

Accordingly, to better understand experimental findings, the comparison with the corresponding monoionic solutions could help to enucleate the single ions effects. Therefore, monoionic solutions of $\mathrm{La}$ and $\mathrm{Cu}$, of absolute compositions equal to the bionic ones, were studied. La uptake in absence of $\mathrm{Cu}$ ions is reported in Figure 1b). La uptake linearly increased with initial La content, and no asymptote was reached in the explored range of concentrations; moreover, once the initial La absolute content is fixed, higher La captures were found in monoionic solutions.

Similarly, $\mathrm{Cu}$ uptake without La ions was performed in the range of $0.5-7.4 \mathrm{mmol} / \mathrm{g}_{\mathrm{STX}}$, (i.e., $635-9531 \mathrm{mg} / \mathrm{L}$ ). $\mathrm{Cu}$ uptake as a function of the initial $\mathrm{Cu}$ content is reported in Figure 2.

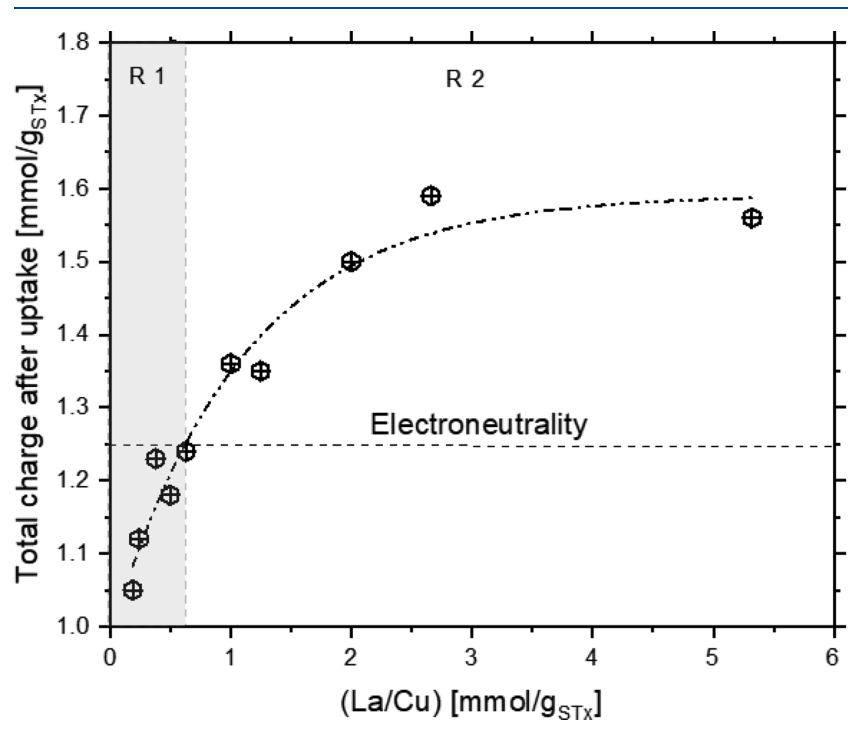

Figure 2. Cu uptake in monoionic solutions by STx.

STx is able to capture $\mathrm{Cu}$ ions from monoionic solutions only at initial $\mathrm{Cu}$ contents lower than $\approx 3.5 \mathrm{mmol} / \mathrm{g}_{\mathrm{STx}}$ and $\mathrm{pH}$ higher than 4.4 .

$\mathrm{Cu}$ adsorption by $\mathrm{Ca}$-montmorillonite was also reported by Bhattacharyya et al., where a gradual increase in metal adsorption was found on increasing $\mathrm{pH}$ from 1 to 6 , up to the precipitation of $\mathrm{Cu}$ hydroxide species. ${ }^{19,30}$ Differences at low $\mathrm{pH}$, observed in this work, can be due to large differences in initial $\mathrm{Cu}$ concentration (this work, 635-9531 mg/L) that in Bhattacharyya et al. never exceeded $50 \mathrm{mg} / \mathrm{L}$. The scarce $\mathrm{Cu}$-clay interactions are also supported by cation exchange calculation. In the hypothesis of capture by cation exchange, the extent of $\mathrm{Cu}$ ions capture should be related to the $\mathrm{Ca}$ ions released in the contacting solution during the uptake step.

In Figure 3, actual $\mathrm{Cu}^{2+}$ capture is compared with the expected one, calculated based on the exchangeable $\mathrm{Ca}^{2+}$ during the uptake reaction. ${ }^{26,27,31}$

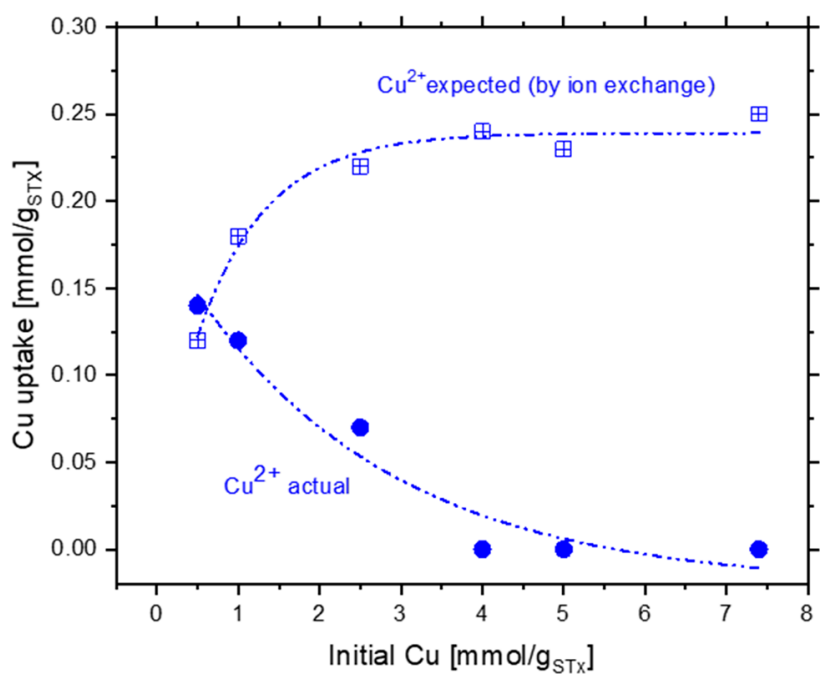

Figure 3. Expected and actual $\mathrm{Cu}$ uptake as a function of initial $\mathrm{Cu}$, calculated on the basis of ion exchange reaction.

Very limited or no exchange reaction was present in all the investigated range of content. Except for the lowest $\mathrm{Cu}$ content, where the two values coincide, $\mathrm{Cu}$ capture is far from that expected, and differences become larger and larger on increasing the $\mathrm{Cu}$ initial content.

Such a behavior could be related to the formation in the solution of copper complexes of different stabilities, which could be able to modify the capture mechanism and drive the uptake extent.

These stable and soluble $\mathrm{Cu}$ species, in equilibrium with the solution, can form in bionic solutions also, thus altering $\mathrm{pH}$ and affecting both $\mathrm{La}$ and $\mathrm{Cu}$ capture.

It has been demonstrated that $\mathrm{pH}$ is a key parameter in the uptake reaction, ${ }^{23,32}$ and it affects the capture mechanisms due to the proton involvement in the reaction. Indeed, protons, small and fast, are able to compete with ions for solid sorbent sites.

Therefore, $\mathrm{pH}$ of bionic solutions was monitored during the experiments. A slight decrease from 4.2 to 3.6 was observed on increasing the $\mathrm{Cu}$ content in the initial solution.

The propensity of $\mathrm{Cu}(\mathrm{II})$ to form aquo-complexes, [Cu$\left.\left(\mathrm{H}_{2} \mathrm{O}\right)_{n}\right]^{2+}(n=1-6)$, has been reported in the literature, ${ }^{33}$ with $\left[\mathrm{Cu}_{2}(\mathrm{OH})_{2}\right]^{2+}$ the most probable species. Due to the formation of such hydroxy-complexes, $\mathrm{Cu}(\mathrm{II})$ hydrolysis occurs at lower $\mathrm{pH}$ as $\mathrm{Cu}$ (II) concentration in solution increases. ${ }^{34} \mathrm{~A} \mathrm{pH}$ decrease was detected which was related to the formation of the $\mathrm{Cu}$ hydroxy-complexes. Indeed, complex formation goes along with proton release according to eq 1

$$
2 \mathrm{Cu}^{2+}+2 \mathrm{H}_{2} \mathrm{O} \leftarrow \rightarrow\left[\mathrm{Cu}_{2}(\mathrm{OH})_{2}\right]^{2+}+2 \mathrm{H}^{+}
$$

The formation of stable aquo- and hydroxy-complexes can explain the uptake trends of both $\mathrm{La}$ and $\mathrm{Cu}$ in bionic solutions when pristine clay is used as the sorbent.

$\mathrm{Cu}$ complexes are also highly stabilized by the presence of the sorbent; indeed, pristine clay is able to capture protons, thus shifting the equilibrium toward the formation of the complexes (eq 1).

Accordingly, the absence of $\mathrm{Cu}$ capture can be explained with the formation of complexes. $\mathrm{Cu}$ aquo-complexes, sterically cluttered and stabilized in solution by their molecular geometry, ${ }^{35}$ can hardly interact with the interlayer capture sites. 
This picture is supported by findings on other sorbent systems, such as active carbon, where the same behavior was found, despite the very different nature of the solid sorbent. ${ }^{25}$ In addition to that, the effect of $\mathrm{pH}$ cannot be discarded too. $\mathrm{pH}$ lower than 4.7 was reported to be critical to obtain any copper uptake in monoionic solutions for sorbents of similar or different natures than those here reported. ${ }^{26,36}$

Therefore, to explain $\mathrm{Cu}$ uptake in bionic solutions, it is reasonable to infer the copresence of both the effects. Moreover, prevention of $\mathrm{Cu}$ uptake appears to be more related to the nature of $\mathrm{Cu}$ species in solution than to the nature of the solid sorbent.

The larger number of protons which accompany the $\mathrm{Cu}$ hydroxy-complexes formation can also interfere with La uptake. Protons, indeed, able to exchange with interlayer cations, compete for capture sites of the clay and lower the La uptake process. $^{23}$

It can be concluded that, despite no direct competition between $\mathrm{Cu}$ and La for the STx uptake sites, the modification of the acid-base condition of the bionic solution and the related equilibria modification results in a $\mathrm{Cu}$ effect on $\mathrm{La}$ behavior. For example, setting the La content at $2.5 \mathrm{mmol} /$ $\mathrm{g}_{\mathrm{ST} x}$, La uptake of $0.60 \mathrm{mmol}_{\mathrm{La}} / \mathrm{g}_{\mathrm{STx}}$ was found for the single ion solution to be compared with 0.26 and $0.30 \mathrm{mmol}_{\mathrm{La}} / \mathrm{g}_{\mathrm{STx}}$ in the case of the bionic ones, depending on the $\mathrm{La} / \mathrm{Cu}$ ratio.

As already reported in the literature for similar systems and monoionic solutions, two different possible interactions for La ions were considered: ion exchange and surface adsorption. ${ }^{23}$ Exchange extent is calculated by the difference between the corresponding total charge and the displaced cations. Replacing ions, La, or protons cannot exceed the total charge of the displaced cations ( $\mathrm{Ca}$ in this case); thus, when cation displacement is constant, the ion exchange process is constant as well.

Accordingly, to analyze in detail the capture mechanism in bionic systems, the interlayer ion composition was measured, and the corresponding charge balance was calculated before and after the uptake process. Indeed, if copper, lanthanum, or protons are captured by the clay via exchange mechanism, a corresponding amount of calcium and, possibly, magnesium, must be replaced to maintain electroneutrality.

With ICP analysis, a constant exchange of Ca ions of about $0.27-0.30 \mathrm{mmol} / \mathrm{g}_{\mathrm{STx}}$, corresponding only to half of the total interlayer $\mathrm{Ca}$ (i.e., $0.54 \mathrm{mmol} / \mathrm{g}_{\mathrm{STx}}$ ), was found, while $\mathrm{Mg}$ was constant and negligible $\left(0.03 \mathrm{mmol} / \mathrm{g}_{\mathrm{STx}}\right)$. This suggests that a threshold value in ion exchange was present; the same behavior was reported for monoionic solutions. ${ }^{23,26}$

Considering that no $\mathrm{Cu}$ capture occurs in bionic solutions, Ca exchange mainly involves La and protons. The only partial replacement of $\mathrm{Ca}$ by $\mathrm{La}$ ions can be explained considering a possible effect of ionic radii of hydrated $\mathrm{Ca}$ and $\mathrm{La}$ ions; indeed, coordination with water molecules also has to be considered because of the aqueous environment of the interlayer.

It is reported in the literature that $\mathrm{Ca}$ ions, forming the hydrate species $\left[\mathrm{Ca}\left(\mathrm{H}_{2} \mathrm{O}\right)_{8}{ }^{2+}\right]$, have an ionic radius of $1.12 \AA$, while $\mathrm{La}$ ion in the hydrate species $\left[\mathrm{La}\left(\mathrm{H}_{2} \mathrm{O}\right)_{9}{ }^{3+}\right]$ presents an ionic radius of $1.25 \AA \AA^{37,38}$ This difference is not so high to prevent replacement without a large distortion, but probably cannot allow a larger $\mathrm{Ca}$ replacement by $\mathrm{La}$ due to steric hindrance. It has to be underlined that large differences in ionic radii are not allowed in the case of interlayer ion exchange to limit structural distortion and preserve phase stability. On this basis, once more, the absence of $\mathrm{Cu}$ uptake can be explained by considering that $\mathrm{Cu}$ in $\left[\mathrm{Cu}\left(\mathrm{H}_{2} \mathrm{O}\right)_{6}\right]^{2+}$ shows an ionic radius of $0.73 \AA$, smaller than that of $\mathrm{Ca}$ ions.

The total STx charge after the uptake reaction can be calculated by summing up the exchanged charges and the nondisplaced ones. In Figure 4, the total charge in the solid

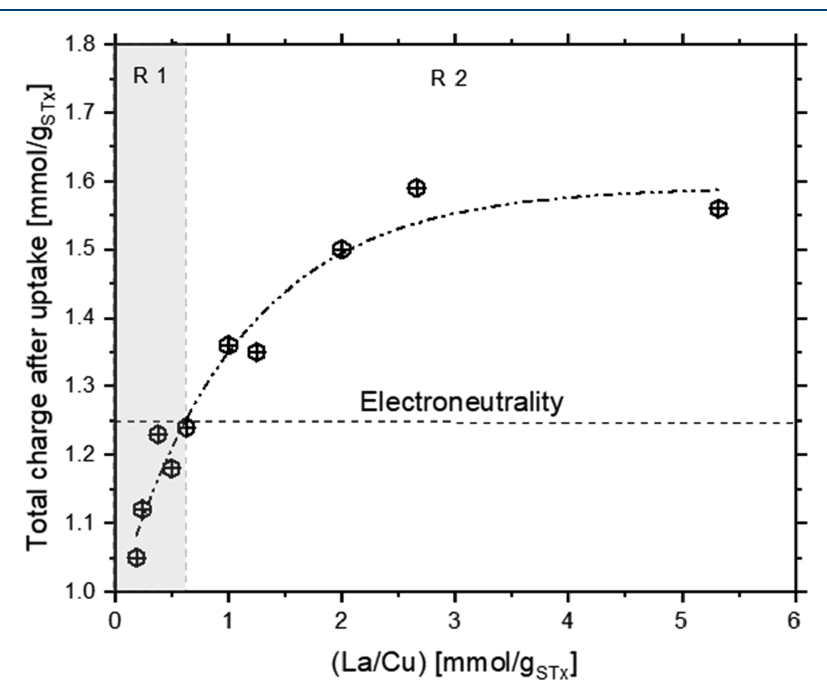

Figure 4. Total charge in STx after uptake reaction as a function of $\mathrm{La} / \mathrm{Cu}$. Dashed line corresponds to electroneutrality; R1 = Region 1 and $\mathrm{R} 2=$ Region 2.

after the uptake reaction is reported as a function of the $\mathrm{La} / \mathrm{Cu}$ ratio in the contacting solution; in this case, no contribution of $\mathrm{Cu}$ ions is present due to the absence of capture.

On increasing the $\mathrm{La} / \mathrm{Cu}$ ratio, the total charge in the solid increases to reach a plateau of about $1.6 \mathrm{mmol}_{\text {charge }} / \mathrm{g}_{\mathrm{STx}}$. In the charge balance (Figure 4), two regions (Region 1 and Region 2) can be evidenced, one at low $\mathrm{La} / \mathrm{Cu}(\mathrm{R} 1)$, where the charge is apparently lower than requested for electroneutrality (i.e., $1.24 \mathrm{mmol}_{\text {charge }} / \mathrm{g}_{\mathrm{STx}}$, gray area in Figure 4$)$, and one where a charge excess is manifest (R2), suggesting a possible unbalancing between the charge "in" and the charge "out". Uptake results of Region 1 are consistent with copper hydrolysis, the related complexes formation, and the associated protons release. Indeed, on increasing the $\mathrm{Cu}$ content, thus decreasing the $\mathrm{La} / \mathrm{Cu}$ ratio (Figure 4, R1), lanthanum uptake is lowered, and the total charge is decreased down to a value apparently below electroneutrality. However, electroneutrality must be preserved; therefore, the presence of protons competing with La ions, thus lowering their uptake, has to be considered. Indeed, the charges measured by ICP analysis, and plotted in Figure 4, underestimate the real number of the ions because protons are not measured by this technique; thus, they are missed in the total charge calculation.

Unfortunately, an attempt to take protons into account in the charge balance did not result in a satisfactory result. Indeed, considering that clay is able to absorb protons, a buffer effect becomes active during the capture process; therefore, $\mathrm{pH}$ variation is probably too small to be detected in such a complex suspension. Thus, a precise evaluation of proton exchanges between the solid and solution through $\mathrm{pH}$ measurement is prevented.

On the other hand, the excess of the incoming charge with respect to the outgoing (R2, Figure 4) can be explained with the presence of an additional surface adsorption contribution. 
Therefore, the asymptotic behavior observed on increasing the $\mathrm{La} / \mathrm{Cu}$ ratio depends on both exchange process saturation and surface adsorption.

To further support this picture, clay-ion interactions were analyzed by XRD measurements of the solid matrix after the uptake processes (Figure 5). Indeed, the position of the basal reflection corresponding to $d_{001}$ is related to the interlayer spacing which, in turn, depends on interlayer composition.

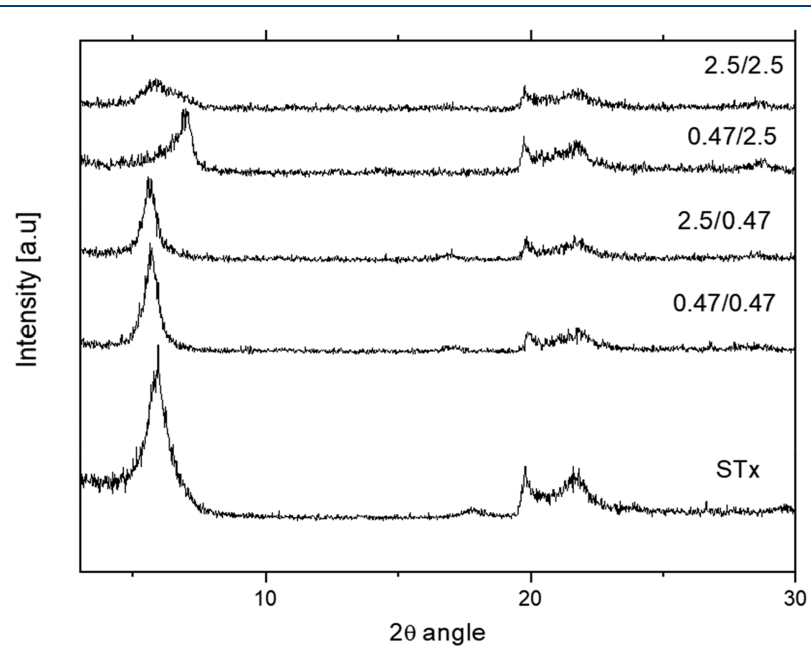

Figure 5. XRD patterns of STx before and after uptake in bionic solutions.

The samples reported in Figure 5 were selected to compare (a) the effect of the equimolar $\mathrm{La}$ and $\mathrm{Cu}$ content, namely, $0.47 / 0.47$ and $2.5 / 2.5$ corresponding to $\mathrm{La} / \mathrm{Cu}=1$, and $(\mathrm{b})$ the effect of the lowest and the highest $\mathrm{La}$ and $\mathrm{Cu}$ contents (i.e., $2.5 / 0.47$ and $0.47 / 2.5$ corresponding to $\mathrm{La} / \mathrm{Cu}=0.19$ and 5.36, respectively).

The complex situation that depends on the relative amounts of $\mathrm{La}$ and $\mathrm{Cu}$ in the initial solution can be summarized as follows:

(1) The position of the basal reflection is always affected by the interaction with the solution.

(2) Diffractograms are not only affected by the relative amount of La and $\mathrm{Cu}$ but also by their absolute content. Indeed, when samples $0.47 / 0.47$ and $2.5 / 2.5$, corre- sponding to the same $\mathrm{La} / \mathrm{Cu}$ ratio, are compared, a very different final situation was found. The ordered situation present in the case of the $0.47 / 0.47$ sample disappears in sample $2.5 / 2.5$. This is quite surprising, considering that very similar $\mathrm{La}$ captures were found $(0.23$ and 0.26 $\mathrm{mmol} / \mathrm{g}_{\mathrm{STx}}$, respectively).

(3) The basal spacing of pristine STx is preserved only in the case of low $\mathrm{Cu}$ content (i.e., samples $0.47 / 0.47$ and 2.5/ 0.47), suggesting that high $\mathrm{Cu}$ content in the contacting solution could result in an interlayer contraction.

For uptake in a monoionic solution, a wider and regular interlayer distance occurred when $\mathrm{Ca}^{2+}$ ions were exchanged with $\mathrm{La}^{3+}$ ions. Due to the La ionic radius $(1.16 \AA)$ and its high coordination number with the interlayer water molecules, the final effect was an increase of the interlayer distance. However, an interlayer contraction was observed when La ions were replaced by protons. ${ }^{23}$

This behavior is evident also in the case of bionic solutions (Figure 5). For instance, in sample $\mathrm{La} / \mathrm{Cu}=0.47 / 0.47$, where the highest $\mathrm{La}$ capture was found $\left(0.24 \mathrm{mmol} / \mathrm{g}_{\mathrm{STx}}\right)$, the interlayer distance increases from $15.4 \AA$ of natural STx to 16.4 $\AA$, due to $\mathrm{Ca}$ exchange with $\mathrm{La}$. On increasing the $\mathrm{Cu}$ content in the solution $(\mathrm{La} / \mathrm{Cu}=0.47 / 2.5)$, a marked contraction of $\mathrm{d}_{001}$ is observed. Once more, this is a confirmation of the presence of a larger number of protons in the interlayer at higher a $\mathrm{Cu}$ solution concentration, which causes the observed lower La capture $\left(0.14 \mathrm{mmol} / \mathrm{g}_{\mathrm{STx}}\right)$.

An even more complex situation is manifest in sample $\mathrm{La} /$ $\mathrm{Cu}=2.5 / 2.5$ (Figure 5). The basal reflection is split in two components, a main reflection, where $\mathrm{d}_{001}$ is unchanged, and a shoulder at higher angles. Despite the broadening of the reflection, it can be assumed that there is the same La interaction, both qualitative and quantitative, as for the 0.47/ 0.47 sample. Indeed, for these samples, La capture of $0.23-$ $0.24 \mathrm{mmol} / \mathrm{g}_{\mathrm{STx}}$ was measured, which justifies constancy in the reflection position. The shoulder position corresponds to that found for the highest $\mathrm{Cu}$ content $(\mathrm{La} / \mathrm{Cu}=0.47 / 2.5)$, and proton contributions can be assumed to explain the reflection position. Moreover, the large broadening of the basal reflection is the result of the interlayer disorders. Indeed, the replaceable Ca positions are randomly occupied by protons and La ions that, respectively, narrow and enlarge the interlayers dimension. No reflection broadening is manifest when only

Table 2. Total, La, and $\mathrm{Cu}$ Ions Contents and Corresponding $\mathrm{pH}$ before and after Uptake Reaction Using Unmodified STx-L6 as Sorbent

\begin{tabular}{|c|c|c|c|c|c|c|c|c|c|}
\hline \multirow[b]{2}{*}{ SET N $^{\circ}$} & \multirow[b]{2}{*}{$\mathrm{La} / \mathrm{Cu}$} & \multicolumn{2}{|c|}{$\mathrm{La}+\mathrm{Cu}[\mathrm{mmol} / \mathrm{gSTx}-\mathrm{L} 6]$} & \multicolumn{2}{|c|}{$\mathrm{La}[\mathrm{mmol} / \mathrm{gSTx}-\mathrm{L} 6]$} & \multicolumn{2}{|c|}{$\mathrm{Cu}[\mathrm{mmol} / \mathrm{gSTx}-\mathrm{L} 6]$} & \multicolumn{2}{|c|}{$\mathrm{pH}$} \\
\hline & & initial & capture & initial & capture & initial & capture & before & after \\
\hline \multirow[t]{4}{*}{0.47} & 1.00 & 0.94 & 0.35 & 0.47 & 0.18 & 0.47 & 0.17 & n.d. & 5.0 \\
\hline & 0.38 & 1.72 & 0.26 & 0.47 & 0.035 & 1.25 & 0.23 & n.d. & 5.0 \\
\hline & 0.24 & 2.47 & 0.11 & 0.47 & 0.035 & 2.00 & 0.07 & 4.3 & 4.4 \\
\hline & 0.19 & 2.97 & 0.035 & 0.47 & 0.035 & 2.50 & 0.00 & n.d. & 4.5 \\
\hline \multirow[t]{4}{*}{1.25} & 2.66 & 1.72 & 0.47 & 1.25 & 0.26 & 0.47 & 0.21 & 4.2 & 4.8 \\
\hline & 1.00 & 2.5 & 0.34 & 1.25 & 0.12 & 1.25 & 0.23 & 4.1 & 4.8 \\
\hline & 0.63 & 3.25 & 0.17 & 1.25 & 0.08 & 2.00 & 0.09 & 4.0 & 4.7 \\
\hline & 0.50 & 3.75 & 0.14 & 1.25 & 0.08 & 2.50 & 0.06 & 3.9 & 4.7 \\
\hline \multirow[t]{3}{*}{2.5} & 5.32 & 2.97 & 0.60 & 2.50 & 0.39 & 0.47 & 0.21 & 4.2 & 5.0 \\
\hline & 2.00 & 3.75 & 0.45 & 2.50 & 0.18 & 1.25 & 0.27 & 3.7 & 4.9 \\
\hline & 1.25 & 4.5 & 0.39 & 2.50 & 0.12 & 2.00 & 0.27 & 3.8 & 4.5 \\
\hline
\end{tabular}


the La ions or La ions and a few protons are present in the interlayer $(\mathrm{La} / \mathrm{Cu}=0.47 / 0.47$ and $\mathrm{La} / \mathrm{Cu}=2.5 / 0.47)$.

All these evidences confirm the capture mechanism proposed above: only Lanthanum interacts, via the exchange mechanism, with the solid sorbent, being able to replace $\mathrm{Ca}$ ions in the interlayer. This exchange mechanism is the only one present if the number of protons present in solution is low, otherwise the competition between protons and La ions sets in.

2. Organoclay (STx-L6). The same experimental campaign, applying the same conditions and procedures, was performed using the organoclay (STx-L6). As remarked in the Materials and Methods section, STx-L6 contained $0.40 \mathrm{mmol}$ of neutral polyamine per gram, intercalated without any ion exchange. ${ }^{14}$ Such a molecular situation assures the presence of amino groups rather than ammonium salts, preserving the maximum ion coordination capability. ${ }^{39}$

In Table 2, total, $\mathrm{Cu}$, and $\mathrm{La}$ concentrations are reported, evaluated by ICP-OES, before and after the uptake process (SET numbers in the table correspond to La concentration).

The organoclay showed an enhanced capture capability, being able to capture $\mathrm{Cu}$ too (Table 2); $\mathrm{Cu}$ uptake was never observed for unmodified STx, where only cation exchange and surface adsorption mechanisms were present. The additional coordination capability, derived from the polyamine presence, can thus be responsible for $\mathrm{Cu}$ capture in this case.

Total uptake values by STx-L6 and STx as a function of La/ $\mathrm{Cu}$ are compared in Figure 6. Total uptake increases on

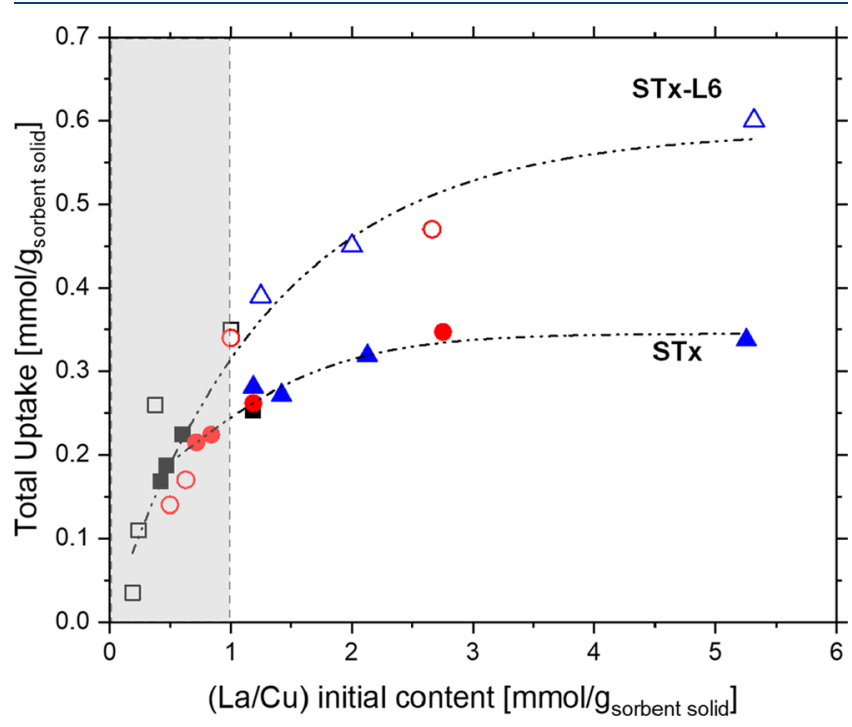

Figure 6. Comparison of total uptake as a function of $\mathrm{La} / \mathrm{Cu}$ in $\mathrm{STx}$ L6 and STx (square, SET 0.47; circle, SET 1.25; triangle, SET 2.5).

increasing $\mathrm{La} / \mathrm{Cu}$ to reach a plateau at the higher $\mathrm{La} / \mathrm{Cu}$ ratios. In the first part of the curves, i.e., La/Cu $<1$ (Figure 6 gray area), very close uptake values were found for the two solids, suggesting that, at the higher $\mathrm{Cu}$ content in bionic solution, similar capture mechanisms are active in both STx and STx-L6.

Considering each ion's capture separately, both $\mathrm{La}$ and $\mathrm{Cu}$ ions are responsible for the total uptake increase, but, while $\mathrm{Cu}$ uptake reaches a plateau on increasing the $\mathrm{La} / \mathrm{Cu}$ ratio, $\mathrm{La}$ uptake is continually growing (Table 2). These results are better illustrated in Figure 7, where specific $\mathrm{La}$ and $\mathrm{Cu}$ uptake values are plotted as a function of the initial $\mathrm{La} / \mathrm{Cu}$.

Lanthanum capture linearly increased on increasing $\mathrm{La} / \mathrm{Cu}$ (Figure 7), i.e., when a larger number of La ions are present in

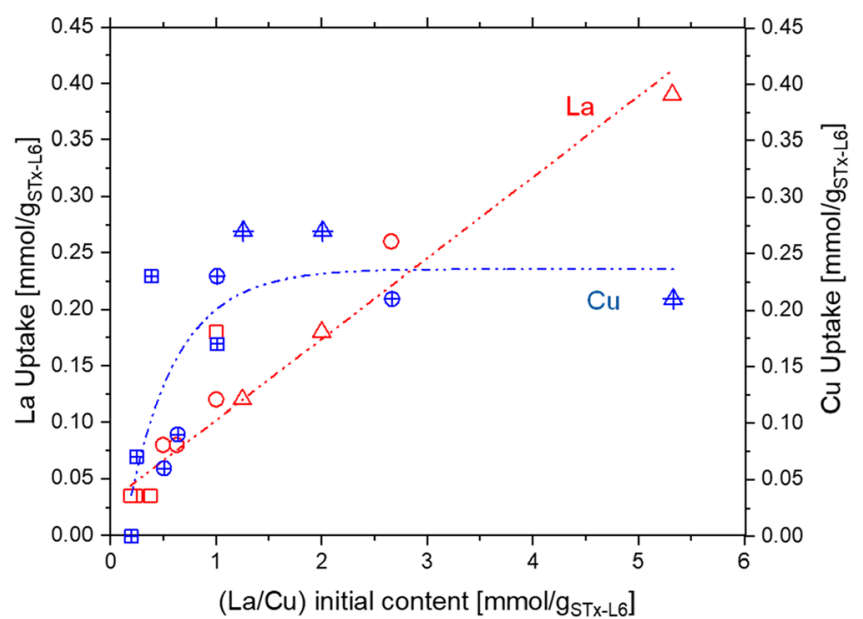

Figure 7. Uptake of $\mathrm{La}$ and $\mathrm{Cu}$ as a function of initial $\mathrm{La} / \mathrm{Cu}$ in STxL6 (square, SET 0.47; circle, SET 1.25; triangle, SET 2.5).

the contacting solution, and the linear behavior is detected at any solution composition. All data are well interpolated by a common regression line, and no asymptote or plateau was found in this case. As already discussed, an asymptotic growth for La uptake in the bionic solutions was observed for the STx system (Figure 1a), and it was associated with a site saturation mechanism, where only a given number of $\mathrm{La}^{3+}$ ions were able to replace a limited number of $\mathrm{Ca}^{2+}$ ions, via ion exchange.

The absence of an asymptotic value for La uptake in the organoclay could be related to an increased buffer capability of the STx-L6 sorbent, in view of the polyamine presence. The polyamine, indeed, could be involved in proton capture, thus lowering proton competition with La ions. At the highest La/ $\mathrm{Cu}$ ratio and for the $2.5 \mathrm{mmol} / \mathrm{g}_{\text {sorbent }}$ of initial $\mathrm{La}$ concentration, La capture resulted $13 \%$ for STx and $16 \%$ for STx-L6.

Unlike STx, STx-L6 is able to capture Cu ions (Table 2); an asymptotic growth was measured where the maximum capture was about $0.21-0.27 \mathrm{mmol}_{\mathrm{Cu}} / \mathrm{g}_{\mathrm{STx}-\mathrm{L} 6}$ at the highest $\mathrm{La} / \mathrm{Cu}$ (Figure 7). To explain STx-L6 behavior, the contribution of the polyamine has to be inferred. It is reported in the literature that ammonia and amino groups form stable complexes with $\mathrm{Cu}$ ions, via a donor bond between a nitrogen-free electron pair and $\mathrm{Cu}$ empty " $\mathrm{d}$ " orbitals. ${ }^{40,41}$ Therefore, considering that no ion exchange was possible between $\mathrm{Ca}$ and $\mathrm{Cu}$ ions, $\mathrm{Cu}$ capture is primarily related to coordination.

It is evident that La does not influence $\mathrm{Cu}$ uptake; indeed, at a fixed $\mathrm{Cu}$ content of $0.47 \mathrm{mmol} / \mathrm{g}_{\mathrm{STx}-\mathrm{L} 6}, \mathrm{Cu}$ uptake ranges between 0.17 and $0.21 \mathrm{mmol} / \mathrm{g}_{\mathrm{STx}-\mathrm{L} 6}$ on increasing the La initial content from 0.47 to $2.5 \mathrm{mmol} / \mathrm{g}_{\mathrm{STx}-\mathrm{L} 6}$ (Table 2).

Also, in the case of STx-L6, the formation of aquocomplexes can be hypothesized to explain $\mathrm{La}$ and $\mathrm{Cu}$ behavior. As already discussed, $\mathrm{pH}$ variation, related to $\mathrm{Cu}$ aquo-complex formation, can explain both $\mathrm{Cu}$ and $\mathrm{La}$ uptake increases on increasing the $\mathrm{La} / \mathrm{Cu}$ ratio. In this case, an additional effect has to be considered, that is, protonation of the amino groups of the polyamine. ${ }^{39,41}$ Such an effect will have a detrimental impact on $\mathrm{Cu}$ uptake.

The possibility of partial polyamine protonation has also been discussed above to explain the increased La capture from $13 \%$ to $16 \%$ of the total, when STx and STx-L6 are used, respectively; in this case, indeed, free protons are partitioned 
between ion exchange and amine protonation, thus resulting in reduced $\mathrm{H}^{+}-\mathrm{La}^{3+}$ competition.

To verify this hypothesis, $\mathrm{pH}$ values before and after the uptake steps were measured. Initial $\mathrm{pH}$ ranged between 4.0 and 3.7, where the lower values corresponded to the highest $\mathrm{Cu}$ content, in line with the discussed proton evolution. At the end of the uptake reaction, a $\mathrm{pH}$ increase was detected. Values between 4.5 and 5.0 were measured depending on the $\mathrm{La} / \mathrm{Cu}$ ratio; once more, the lower value corresponded to the highest $\mathrm{Cu}$ content. Such evidence is in line with the already discussed buffer effect of the polyamine and the consequent lower competition between $\mathrm{H}^{+}$and $\mathrm{La}^{3+}$ for the exchanging sites. It has to be underlined that, in the case of unmodified STx, $\mathrm{pH}$ at the end of the reaction never exceeded 4.5-4.6.

The high and constant $\mathrm{Cu}$ uptake, observed at the highest La content, can also be explained considering the polyamine protonation; indeed, $\mathrm{Cu}$ uptake is the result of a balance between two opposite effects. Despite the decreased coordination capability, the buffering effect shifted $\mathrm{pH}$ toward values more favorable to $\mathrm{Cu}$ capture (i.e., $\mathrm{pH}>4.4$ ), and this effect is well evidenced in Figure 8 where $\mathrm{Cu}$ uptake in

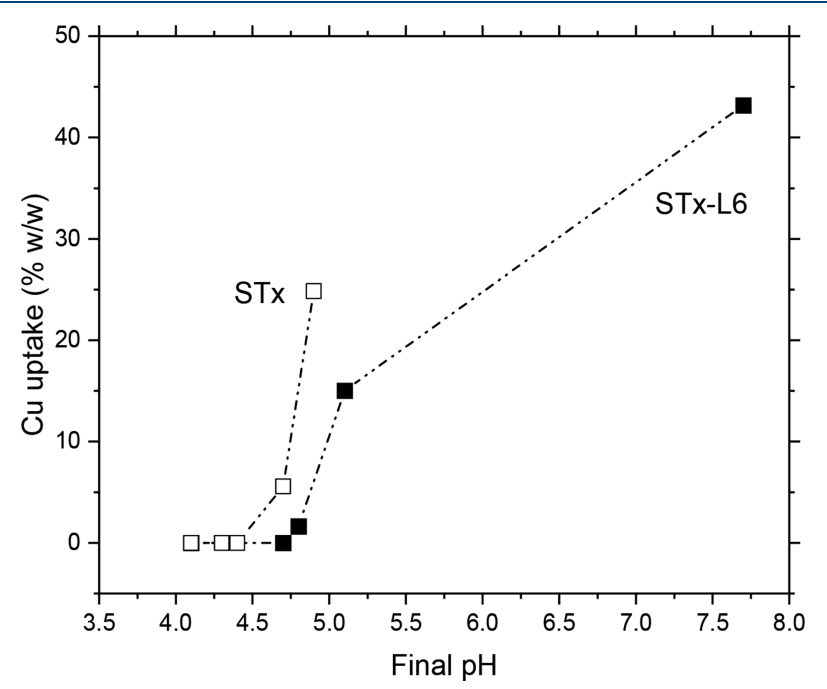

Figure 8. $\mathrm{Cu}$ uptake in monoionic solutions as a function of reaction $\mathrm{pH}$ for STx and STx-L6.

monoionic solutions, i.e., without any possible La influence, is plotted as a function of final $\mathrm{pH}$. Points in the figure refer to experiments performed with STx and STx-L6 sorbents at corresponding initial $\mathrm{Cu}$ concentration.

Monoionic solutions evidenced as $\mathrm{Cu}$ uptake is largely influenced by $\mathrm{pH}$; $\mathrm{Cu}$ uptake increases almost linearly on increasing $\mathrm{pH}$, while the highest $\mathrm{Cu}$ uptake, observed at $\mathrm{pH}$ 7.8 , could be the result of both coordination and precipitation of $\mathrm{Cu}$ hydroxides species. This last effect cannot occur in the case of bionic solutions where always lower $\mathrm{pH}$ values (i.e., 4.5-5) are reached.

In the case of STx-L6, two different mechanisms of ions uptake can be considered, one implying interlayer cation exchange and the other implying coordination with the polyamine; moreover, surface adsorption contribution cannot be discarded, too. To evaluate the contribution of each mechanism to determine the final uptake, some hypotheses have to be verified:

(a) Only lanthanum is involved in the exchange process, since no copper was captured by pristine clays. (b) Only copper is coordinated to the polyamine, in view of its preferential interaction with amino groups.

The exchange reaction can be evaluated by considering the displacement of $\mathrm{Ca}$ ions and comparing it with La uptake. As already discussed for pristine STx, Ca ions are replaced by La ions to maintain the charge balance of the structure. Constant Ca ions, $0.30-0.31 \mathrm{mmol} / \mathrm{g}_{\mathrm{STx}-\mathrm{L} 6}$, were always measured in the solutions after uptake, confirming that, also in this case, interlayer Ca ions can be replaced only partially, but at a lower extent than $\operatorname{STx}\left(0.54 \mathrm{mmol} / \mathrm{g}_{\mathrm{STx}-\mathrm{L} 6}\right)$. The polyamine can interact with some $\mathrm{Ca}$ ions, thus preventing their removal and/ or cluttering of the interlayer, thus hampering access to La. The total exchanged charge only corresponds to a constant theoretical La capture of $0.15-0.16 \mathrm{mmol} / \mathrm{g}_{\mathrm{STX}-\mathrm{L} 6}$, far below the experimental capture reported in Table 2.

In Figure 9, the La uptake expected via the exchange process and the actual La captured are compared as a function of La/ $\mathrm{Cu}$ ratio.

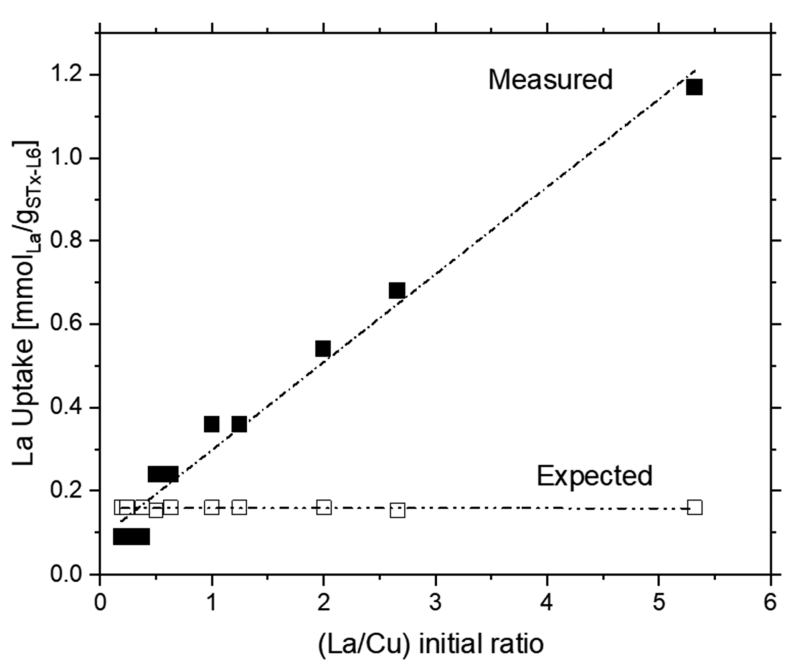

Figure 9. Comparison between the measured La uptake and the expected one on the basis of the ion exchange mechanism only.

It is evident that lanthanum uptake cannot occur via the exchange mechanism only because an excess of charge would be present in the solid; therefore, surface interactions must account for the excess La. Furthermore, the La capture, lower than charge balance, observed at high $\mathrm{Cu}$ content, once more confirms the presence of competition between protons and $\mathrm{La}$ ions in the exchange reaction.

It has been hypothesized that, in the case of bionic solutions, coordination does not involve La ions, in view of the higher affinity of amino groups for $\mathrm{Cu}$. To confirm this point, in Figure 10, $\mathrm{La}$ and $\mathrm{Cu}$ uptake in monoionic and bionic solutions with unmodified STx and modified STx-L6 are compared at a fixed $\mathrm{La} / \mathrm{Cu}=5.3$; modified organoclay always showed better performances The large improvement of La capture, due to the polyamine, also in the monoionic solutions, suggests that also La can be coordinated by the polyamine, ${ }^{27}$ when no $\mathrm{Cu}$ is present. In bionic solutions, the most remarkable effect of the polyamine is on $\mathrm{Cu}$ uptake, that was absent with unmodified STx, while the limited increase of La uptake in a bionic solution can be due only to the surface adsorption discussed above. 


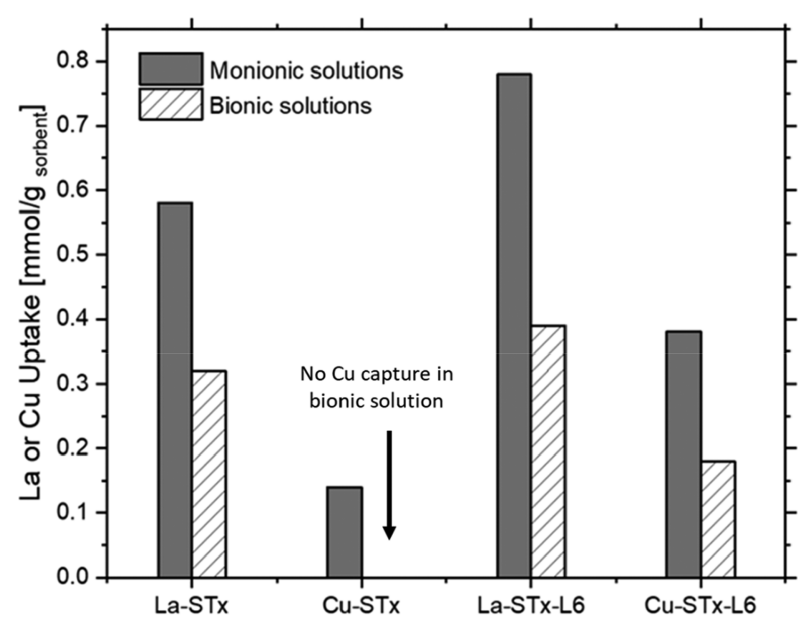

Figure 10. Comparison of La uptake in monoionic and bionic solutions by different sorbents.

\section{CONCLUSIONS}

Modified organoclay always showed better performances. The most remarkable effect of the polyamine is $\mathrm{Cu}$ uptake, which was absent with unmodified STx. As already reported in the literature for similar systems and monoionic solutions, three different ion-sorbent interactions are possible: ion exchange, surface adsorption (due to the clay), and coordination due to the intercalated polyamine.

Only lanthanum is involved in the exchange process, since no copper was captured by pristine clays, whereas only copper is coordinated to the polyamine, in view of its preferential interaction with amino groups.

Capture is influenced by the formation of stable $\mathrm{Cu}$ aquoand hydroxy-complexes, which alters the solution $\mathrm{pH}$. In the case of the unmodified clay, $\mathrm{Cu}$ aquo-complexes, sterically cluttered, are not able to interact with the interlayer, thus $\mathrm{Cu}$ uptake is prevented. $\mathrm{Cu}$ hydroxy-complexes are also responsible for La uptake behavior. Indeed, the larger number of protons which accompany the $\mathrm{Cu}$ hydroxy-complexes formation, small and fast, are able to compete with La ions for capture sites.

\section{ASSOCIATED CONTENT}

\section{SI Supporting Information}

The Supporting Information is available free of charge at https://pubs.acs.org/doi/10.1021/acs.iecr.0c05333.

Table S1: Composition of leached mobile phones solution. Table S2: Solution composition of WEEE scraps. Figure S1: Plot of HYDRA-MEDUSA calculation for $\mathrm{La}$ and $\mathrm{Cu}$ ions solutions. (PDF)

\section{AUTHOR INFORMATION}

\section{Corresponding Author}

Cinzia Cristiani - Dipartimento di Chimica, Materiali e Ingegneria Chimica "Giulio Natta", Politecnico di Milano, 20133 Milano, Italy; (이이.org/0000-0001-6045-1186; Email: cinzia.cristiani@polimi.it

\section{Authors}

Elena Maria Iannicelli-Zubiani - Dipartimento di Chimica, Materiali e Ingegneria Chimica "Giulio Natta", Politecnico di Milano, 20133 Milano, Italy; ㅇo orcid.org/0000-0002$1238-8773$
Maurizio Bellotto - Dipartimento di Chimica, Materiali e Ingegneria Chimica "Giulio Natta", Politecnico di Milano, 20133 Milano, Italy

Giovanni Dotelli - Dipartimento di Chimica, Materiali e Ingegneria Chimica "Giulio Natta", Politecnico di Milano, 20133 Milano, Italy

Paola Gallo Stampino - Dipartimento di Chimica, Materiali e Ingegneria Chimica "Giulio Natta", Politecnico di Milano, 20133 Milano, Italy

Saverio Latorrata - Dipartimento di Chimica, Materiali e Ingegneria Chimica "Giulio Natta", Politecnico di Milano, 20133 Milano, Italy; 이이.org/0000-0001-7087-553X

Gianguido Ramis - Dipartimento di Ingegneria Civile, Chimica e Ambientale, Università di Genova, 16145 Genova, Italy

Elisabetta Finocchio - Dipartimento di Ingegneria Civile, Chimica e Ambientale, Università di Genova, 16145 Genova, Italy

Complete contact information is available at:

https://pubs.acs.org/10.1021/acs.iecr.0c05333

\section{Author Contributions}

C.C. and E.F.: Conceptualization, methodology, supervision, writing, review, and editing. EM.I.Z.: Investigation, methodology, validation, and writing the original draft. M.B.: validation and formal analysis. G.D.: validation, formal analysis, and funding acquisition. E.F. and C.C.: Investigation, validation, supervision, writing, review, and editing. S.L.: Data curation and investigation. G.R.: Validation, writing, review, and editing. P.G.S.: Resource and data curation.

\section{Notes}

The authors declare no competing financial interest.

\section{ACKNOWLEDGMENTS}

Ms. Giuseppina Gasti and Ms. Gigliola Clerici are acknowledged for experimental support.

\section{REFERENCES}

(1) Feng, M.; Zhang, P.; Zhou, H. C.; Sharma, V. K. Water-Stable Metal-Organic Frameworks for Aqueous Removal of Heavy Metals and Radionuclides: A Review. Chemosphere 2018, 209, 783-800.

(2) Wen, J.; Fang, Y.; Zeng, G. Progress and Prospect of Adsorptive Removal of Heavy Metal Ions from Aqueous Solution Using MetalOrganic Frameworks: A Review of Studies from the Last Decade. Chemosphere 2018, 201, 627-643.

(3) Matłok, M.; Petrus, R.; Warchol, J. K. Equilibrium Study of Heavy Metals Adsorption on Kaolin. Ind. Eng. Chem. Res. 2015, 54 (27), 6975-6984.

(4) Kaya, M. Recovery of Metals and Nonmetals from Electronic Waste by Physical and Chemical Recycling Processes. Waste Manage. 2016, 57, 64-90.

(5) Fresco-Cala, B.; Cárdenas, S. Potential of Nanoparticle-Based Hybrid Monoliths as Sorbents in Microextraction Techniques. Anal. Chim. Acta 2018, 1031, 15-27.

(6) Jawad, A.; Peng, L.; Liao, Z.; Zhou, Z.; Shahzad, A.; Ifthikar, J.; Zhao, M.; Chen, Z.; Chen, Z. Selective Removal of Heavy Metals by Hydrotalcites as Adsorbents in Diverse Wastewater: Different Intercalated Anions with Different Mechanisms. J. Cleaner Prod. 2019, 211, 1112.

(7) Lourenço, M. A. O.; Figueira, P.; Pereira, E.; Gomes, J. R. B.; Lopes, C. B.; Ferreira, P. Simple, Mono and Bifunctional Periodic Mesoporous Organosilicas for Removal of Priority Hazardous Substances from Water: The Case of Mercury(II). Chem. Eng. J. 2017, 322, 263-274. 
(8) Ngambia, A.; Ifthikar, J.; Shahib, I. I.; Jawad, A.; Shahzad, A.; Zhao, M.; Wang, J.; Chen, Z.; Chen, Z. Adsorptive Purification of Heavy Metal Contaminated Wastewater with Sewage Sludge Derived Carbon-Supported Mg(II) Composite. Sci. Total Environ. 2019, 691, 306-321.

(9) Ifthikar, J.; Jiao, X.; Ngambia, A.; Wang, T.; Khan, A.; Jawad, A.; Xue, Q.; Liu, L.; Chen, Z. Facile One-Pot Synthesis of Sustainable Carboxymethyl Chitosan - Sewage Sludge Biochar for Effective Heavy Metal Chelation and Regeneration. Bioresour. Technol. 2018, 262 (April), 22-31.

(10) Ali, J.; Wang, H.; Ifthikar, J.; Khan, A.; Wang, T.; Zhan, K.; Shahzad, A.; Chen, Z.; Chen, Z. Efficient, Stable and Selective Adsorption of Heavy Metals by Thio-Functionalized Layered Double Hydroxide in Diverse Types of Water. Chem. Eng. J. 2018, 332, 387397.

(11) Qin, L.; Yan, L.; Chen, J.; Liu, T.; Yu, H.; Du, B. Enhanced Removal of $\mathrm{Pb} 2+, \mathrm{Cu} 2+$, and $\mathrm{Cd} 2+$ by Amino-Functionalized Magnetite/Kaolin Clay. Ind. Eng. Chem. Res. 2016, 55 (27), 73447354.

(12) Kumríc, K. R.; Dukic, A. D. S. B.; Trtić-Petrović, T. M.; Vukelić, N. S.; Stojanović, Z.; Grbović Novaković, J. D.; Matović, L. L. Simultaneous Removal of Divalent Heavy Metals from Aqueous Solutions Using Raw and Mechanochemically Treated Interstratified Montmorillonite/Kaolinite Clay. Ind. Eng. Chem. Res. 2013, 52 (23), 7930-7939.

(13) Chen, Z.; Jawad, A.; Liao, Z.; Zhou, Z.; Khan, A.; Wang, T.; Ifthikar, J.; Shahzad, A.; Chen, Z. Fe-MoS4: An Effective and Stable LDH-Based Adsorbent for Selective Removal of Heavy Metals. ACS Appl. Mater. Interfaces 2017, 9 (34), 28451-28463.

(14) Cristiani, C.; Iannicelli-Zubiani, E. M.; Dotelli, G.; Finocchio, E.; Gallo Stampino, P.; Licchelli, M. Polyamine-Based Organo-Clays for Polluted Water Treatment: Effect of Polyamine Structure and Content. Polymers (Basel, Switz.) 2019, 11 (5), 897.

(15) Finocchio, E.; Baccini, I.; Cristiani, C.; Dotelli, G.; Gallo Stampino, P.; Zampori, L. Hybrid Organo-Inorganic Clay with Nonionic Interlayers. Mid- and near-IR Spectroscopic Studies. J. Phys. Chem. A 2011, 115 (26), 7484-7493.

(16) Zampori, L.; Gallo Stampino, P.; Dotelli, G. Adsorption of Nitrobenzene and Orthochlorophenol on Dimethyl Ditallowyl Montmorillonite: A Microstructural and Thermodynamic Study. Appl. Clay Sci. 2009, 42 (3-4), 605-610.

(17) Zampori, L.; Dotelli, G.; Gallo Stampino, P.; Cristiani, C.; Zorzi, F.; Finocchio, E. Thermal Characterization of a Montmorillonite, Modified with Polyethylene-Glycols (PEG1500 and PEG4000), by in Situ HT-XRD and FT IR: Formation of a HighTemperature Phase. Appl. Clay Sci. 2012, 59-60, 140-147.

(18) Miranda, R. A.; Finocchio, E.; Llorca, J.; Medina, F.; Ramis, G.; Sueiras, J. E.; Segarra, A. M. Synthesis and Characterization of Poly-lLeucine Initialized and Immobilized by Rehydrated Hydrotalcite: Understanding Stability and the Nature of Interaction. Phys. Chem. Chem. Phys. 2013, 15 (37), 15645-15659.

(19) Bhattacharyya, K. G.; Gupta, S. Sen. Removal of $\mathrm{Cu}(\mathrm{II})$ by Natural and Acid-Activated Clays: An Insight of Adsorption Isotherm, Kinetic and Thermodynamics. Desalination 2011, 272 (1-3), 66-75.

(20) De Pablo, L.; Chávez, M. L.; Abatal, M. Adsorption of Heavy Metals in Acid to Alkaline Environments by Montmorillonite and CaMontmorillonite. Chem. Eng. J. 2011, 171 (3), 1276.

(21) Malamis, S.; Katsou, E. A Review on Zinc and Nickel Adsorption on Natural and Modified Zeolite, Bentonite and Vermiculite: Examination of Process Parameters, Kinetics and Isotherms. J. Hazard. Mater. 2013, 252-253, 428-461.

(22) Iannicelli-Zubiani, E. M.; Cristiani, C.; Dotelli, G.; Stampino, P. G.; Bengo, I. Lanthanum Uptake by Clays and Organo-Clays: Effect of the Polymer. Procedia Environ. Sci. Eng. Manag. 2014, 1 (1), 25-29.

(23) Iannicelli-Zubiani, E. M.; Cristiani, C.; Dotelli, G.; Gallo Stampino, P.; Pelosato, R.; Mesto, E.; Schingaro, E.; Lacalamita, M. Use of Natural Clays as Sorbent Materials for Rare Earth Ions: Materials Characterization and Set up of the Operative Parameters. Waste Manage. 2015, 46, 546.
(24) Iannicelli-Zubiani, E. M.; Cristiani, C.; Dotelli, G.; Stampino, P. G.; Pelosato, R.; Finocchio, E. Effect of PH in the Synthesis of Organo-Clays for Rare Earths Removal. Environ. Eng. Manage. J. 2017, 16 (8), 1719-1728.

(25) Iannicelli-Zubiani, E. M.; Gallo Stampino, P.; Cristiani, C.; Dotelli, G. Enhanced Lanthanum Adsorption by Amine Modified Activated Carbon. Chem. Eng. J. 2018, 341, 75-82.

(26) Iannicelli-Zubiani, E. M.; Cristiani, C.; Dotelli, G.; Gallo Stampino, P. Recovery of Valuable Metals from Electronic Scraps by Clays and Organo-Clays: Study on Bi-Ionic Model Solutions. Waste Manage. 2017, 60, 582.

(27) Cristiani, C.; Iannicelli-Zubiani, E. M.; Bellotto, M.; Dotelli, G.; Finocchio, E.; Latorrata, S.; Ramis, G.; Gallo Stampino, P. Capture and Release Mechanism of La Ions by New Polyamine-Based Organoclays: A Model System for Rare-Earths Recovery in Urban Mining Process. J. Environ. Chem. Eng. 2021, 9 (1), 104730.

(28) Iannicelli-Zubiani, E. M.; Giani, M. I.; Recanati, F.; Dotelli, G.; Puricelli, S.; Cristiani, C. Environmental Impacts of a Hydrometallurgical Process for Electronic Waste Treatment: A Life Cycle Assessment Case Study. J. Cleaner Prod. 2017, 140, 1204.

(29) Cristiani, C.; Bellotto, M.; Dotelli, G.; Latorrata, S.; Ramis, G.; Gallo Stampino, P.; Zubiani, E. M. I.; Finocchio, E. Rare Earths (La, $\mathrm{Y}$, and Nd) Adsorption Behaviour towards Mineral Clays and Organoclays: Monoionic and Trionic Solutions. Minerals 2021, 11 (1), 30 .

(30) Bhattacharyya, K. G.; Gupta, S. S. Kaolinite, Montmorillonite, and Their Modified Derivatives as Adsorbents for Removal of $\mathrm{Cu}(\mathrm{II})$ from Aqueous Solution. Sep. Purif. Technol. 2006, 50 (3), 388-397.

(31) Iannicelli-Zubiani, E. M.; Cristiani, C.; Dotelli, G.; Gallo Stampino, P.; Pelosato, R.; Mesto, E.; Schingaro, E.; Lacalamita, M. Use of Natural Clays as Sorbent Materials for Rare Earth Ions: Materials Characterization and Set up of the Operative Parameters. Waste Manage. 2015, 46, 546-556.

(32) Ifthikar, J.; Shahib, I. I.; Sellaoui, L.; Jawad, A.; Zhao, M.; Chen, Z.; Chen, Z. PH Tunable Anionic and Cationic Heavy Metal Reduction Coupled Adsorption by Thiol Cross-Linked Composite: Physicochemical Interpretations and Fixed-Bed Column Mathematical Model Study. Chem. Eng. J. 2020, 401 (June), 126041.

(33) Galván-García, E. A.; Agacino-Valdés, E.; Franco-Pérez, M.; Gómez-Balderas, R. $[\mathrm{Cu}(\mathrm{H} 2 \mathrm{O}) \mathrm{n}] 2+(\mathrm{n}=1-6)$ Complexes in Solution Phase: A DFT Hierarchical Study. Theor. Chem. Acc. 2017, 136 (3), $1-14$.

(34) Powell, K. J.; Brown, P. L.; Byrne, R. H.; Gajda, T.; Hefter, G.; Sjöberg, S.; Wanner, H. Chemical Speciation of Environmentally Significant Metals with Inorganic Ligands. PART 2: The $\mathrm{Cu} 2+-\mathrm{OH}-$, $\mathrm{Cl}-, \mathrm{CO} 32-$, SO42-, and PO43- Systems (IUPAC Technical Report). Pure Appl. Chem. 2007, 79 (5), 895-950.

(35) Persson, I.; Lundberg, D.; Bajnóczi, É. G.; Klementiev, K.; Just, J.; Sigfridsson Clauss, K. G. V. EXAFS Study on the Coordination Chemistry of the Solvated Copper(II) Ion in a Series of Oxygen Donor Solvents. Inorg. Chem. 2020, 59 (14), 9538-9550.

(36) Albadarin, A. B.; Mo, J.; Glocheux, Y.; Allen, S.; Walker, G.; Mangwandi, C. Preliminary Investigation of Mixed Adsorbents for the Removal of Copper and Methylene Blue from Aqueous Solutions. Chem. Eng. J. 2014, 255, 525-534.

(37) Persson, I. Hydrated Metal Ions in Aqueous Solution: How Regular Are Their Structures? Pure Appl. Chem. 2010, 82 (10), 19011917.

(38) D’Angelo, P.; Zitolo, A.; Migliorati, V.; Chillemi, G.; Duvail, M.; Vitorge, P.; Abadie, S.; Spezia, R. Revised Ionic Radii of Lanthanoid(III) Ions in Aqueous Solution. Inorg. Chem. 2011, 50 (10), 4572-4579.

(39) Bencini, A.; Bianchi, A.; Garcia-Espana, E.; Micheloni, M.; Ramirez, J. A. Proton Coordination by Polyamine Compounds in Aqueous Solution. Coord. Chem. Rev. 1999, 188, 97.

(40) Hathaway, B. J.; Tomlinson, A. G. Copper(u) Ammonia Complexes. Coord. Chem. Rev. 1970, 5 (iii), 1-43.

(41) Basallote, M. G.; Doménech, A.; Ferrer, A.; García-España, E.; Llinares, J. M.; Máñez, M. A.; Soriano, C.; Verdejo, B. Synthesis and 
$\mathrm{Cu}$ (II) Coordination of Two New Hexaamines Containing Alternated Propylenic and Ethylenic Chains: Kinetic Studies on PH-Driven Metal Ion Slippage Movements. Inorg. Chim. Acta 2006, 359 (7), 2004-2014. 